\title{
The Influence of Anadara Granosa's Shell Waste as a Substitute of Fine Aggregate in Mixed Asphalt Concrete Wearing Course (AC-WC)
}

\author{
Ika Sulianti ${ }^{1, *}$ Ibrahim $^{1}$ Indah Ayu Wiloka ${ }^{1}$ Reta Iftitah Sari ${ }^{1}$ \\ ${ }^{I}$ Civil Engineering Department, State Polytechnic of Sriwijaya \\ Jl. Srijaya Negara Bukit Besar Palembang 30139, South Sumatera - Indonesia \\ "Corresponding author. Email: ikasulianti74@gmail.com
}

\begin{abstract}
Flexible pavement is pavement which generally uses a mixture of asphalt as the surface layer and grained material as the layer underneath which consists of coarse aggregate and fine aggregate mixed with asphalt. With some research on asphalt in pavement mixing, natural materials can be replaced or mixed with other materials. This research was carried out with the aim to find out whether an Andara Granosa's Shell Waste can improve the quality of a better road pavement. In this case using an Andara Granosa's Shell Waste as a substitute for fine aggregate material. To determine the effect of Andara Granosa's Shell Waste produced as a substitute for fine aggregates on Marshall characteristics and how the physical properties of asphalt when mixed with Andara Granosa's Shell Waste as a substitute for fine aggregates on the mixing of Asphalt Concrete Wearing Course (AC - WC). This research method uses test material in the laboratory using an Andara Granosa's Shell Waste $(0 \%, 25 \%, 50 \%, 75 \%$ and $100 \%)$ with asphalt content $(5 \%, 5.5 \%$ and 6\%). After testing the mixed design material, the optimum asphalt content is obtained at 6\%. Then the Marshall test is performed to obtain the Marshall characteristic value. In Marshall test, the optimum value was obtained using a mixture of shellfish waste in Variation 2 with an asphalt content of 5.5\%. The characteristic stability value is $3479.0 \mathrm{~kg}$. The value of flow is 3,817, VIM (Voids in the mix) is 3,847\%, VMA (Voids in the mineral aggregate) is 22,272\%, VFA (Voids filles asphalt) is 82,727\% and MQ (Marshall Quotient) is $59272.3 \mathrm{~kg} / \mathrm{mm}$. As the final result, the best variation of Anadara Granosa's Shell Waste as a substitute for fine aggregate on the mixing of Asphalt Concrete Wearing Course (AC - WC) based on General Spesification 2010 Bina Marga division VI is variation 2 with 5.5\% asphalt content.
\end{abstract}

Keywords: Anadara Granosa's, Shell Waste, Asphalt Concrete Wearing Course (AC WC), Marshall

\section{INTRODUCTION}

Road pavement is a layer of pavement that is located between the subgrade layer and the wheels of the vehicle, which has a function to provide services to transportation, and during its service period it is hoped that significant damage will not occur. [1]

Asphalt is a natural material with hydrocarbon chemical components, the results of exploration with a black color are plastic to liquid, insoluble in aqueous solutions of acids and alkalis or water, but mostly soluble in aether, $\mathrm{CS}_{2}$ benzene and chloroform. [2] Utilization of green scallop shell waste as fine aggregate in the asphalt mixture is an appropriate and strategic step. From the results of the Marshall test analysis, it is known that fine aggregate with green clam shells gives strength

Marshall characteristics that are still qualify the specifications based on Indonesian National Standard (2008). The Marshall characteristic value of the Sand Sheet B (SS-B) mixture using natural sand and green clam shells as fine aggregate at asphalt content of $8.48 \%$ had a marshall stability value of $1737.69 \mathrm{~kg}$, marshall quotient $3.60 \mathrm{kN} / \mathrm{mm}$, film thikness $8.03 \mathrm{vm}$, and the volume of water void $5.80 \%$. [3]

Based on the existence of previous research on shellfish waste as a substitate fine aggregates in asphalt mixture, it becomes one of the bases for further research 
on different types of shellfish waste, on this research will use Anadara Granosa's shell waste.

The use of blood clams itself produces Anadara Granosa's shell waste which can pollute the environment and lack of knowledge to using this anadara's shell waste. This is one of the inspirations to conduct further research by using this Anadara Granosa's shell waste as a substitute of fine aggregates in the asphalt pavement mixture.

This research was carried out with the aim to find out whether Anadara Granosa's shell waste could improve the quality of pavement to be better. In this study, anadara granosa's waste is used as a substitute fine aggregate in Asphalt Concrete Wearing Course (AC-WC).

\section{MATERIALS AND METHODS}

This research was conducted in the following steps:

\subsection{Materials}

The asphalt used is $60 / 70$ penetration solid asphalt. The waste of shells used in this research is from Pasuruan City. The coarse aggregate used in this study is a split from PT. Possabara Indonesia. Fine Aggregate comes from Tanjung Raja, South Sumatra. And for filler used cement from PT. Semen Baturaja.

\subsection{Physical Properties of Materials Test}

Testing the physical properties of the material is a step to determine whether the aggregate is in accordance with the gradation that has been decided based on SNI specifications.

Testing the physical properties of the material consists of:

Aggregates Physical Properties Test: Sieve Analysis [4], Coarse Spesific Gravity and Absorption [5], Fine Spesific Gravity and Absorption [6] and Abration Test [7]

Asphalt Physical Properties Test: Asphalt

Spesific Gravity [8], Asphalt Softening Point [9]and

Asphalt Penetration [10]

Portland Cement Physical Properties Test:

Cement Spesific Gravity [11] and Cement

Consistency [12]

\subsection{Job Mix Formula (JMF)}

The determination of the composition of the mixture is obtained from the results of the tested material data and make samples.

Manufacture of test objects in accordance with five variations :

- Variation 1 : 0\% seashell waste and 100\% sand

- Variation $2: 25 \%$ seashell waste and $75 \%$ sand

- Variation $3: 50 \%$ seashell waste and 50\% sand

- Variation $4: 75 \%$ seashell waste and $25 \%$ sand

- Variation 5 : 100\% seashell waste and 0\% sand

\subsection{Making samples (normal samples and variations)}

Make 3 samples normal with different asphalt content $(5 \% ; 5.5 \% ; 6 \%)$ and also make 5 variations based on Job Mix Formula (JMF)

\subsection{Determining the Optimum Asphalt Content}

To determine the optimum asphalt content, the first thing to do is make a normal samples, do a marshall test and data analysis. The optimum asphalt content is a qualified sample based on General Spesification Bina Marga 2010 division VI. In this research, the optimum asphalt content is $6 \%$

\subsection{Marshall Test}

After making the test object, the Marshall test was carried out. In Marshall test, the stability and flow values listed will be obtained on Marshall tool.

\subsection{Data Analysis}

Data analysis is analyzing data that has been obtained during the Marshall test.

\section{RESULT AND DISCUSSION}

\subsection{Test Result}

Research data on new materials include testing of the physical properties of aggregates, aggregates that used in this test is an aggregates in the form of split stones, fine aggregates in the form of sand and a mixture of shellfish waste, cement and testing of the physical properties of asphalt.

\subsection{Fine Aggregates Physical Properties Test}

Physical Properties Test of Fine Aggregates is testing an aggregate based on SNI standards and based 
on the existing procedures in SNI. The results of tests carried out on each material in the form of sand and shellfish waste are shown on Table 1.

existing procedures in SNI. The results of tests carried out on each material in the form of a $1 / 2$ split and $1 / 1$ split are shown on Table 2.

\subsection{Asphalt Physical Properties Test}

Asphalt testing is a test which carried out based on SNI standards and based on existing procedures in SNI. The results of each asphalt test are shown on Table 3.

\subsection{Coarse Aggregates Physical Properties Test}

Coarse Aggregates Physical Properties Test is testing an aggregates based on SNI standards and based on

\subsection{Portland Cement Physical Properties Test}

Portland Cement Physical Properties Test is a test of cement which tested based on SNI standards and based on existing procedures in SNI. The results of the tests of cement as a filler are shown on Table 4.

Table 1. Test Result of Fine Aggregates Physical Properties Test

\begin{tabular}{|c|c|c|c|c|}
\hline \multirow{3}{*}{ Kind of Test } & & & \multirow[b]{3}{*}{ Unit } & \multirow{3}{*}{ Spesification } \\
\hline & \multicolumn{2}{|c|}{ Fine Aggregates } & & \\
\hline & Sand & $\begin{array}{l}\text { Shells } \\
\text { Waste }\end{array}$ & & \\
\hline Sieve Analysis & 3,34 & 3,57 & - & \\
\hline Bulk Spesific Gravity & 2,50 & 2,49 & - & $\operatorname{Min} 2,5$ \\
\hline SSD Spesific Gravity & 2,56 & 2,65 & - & $\operatorname{Min} 2,5$ \\
\hline Absorption & 2,51 & 7,34 & $\%$ & $\operatorname{Max} 3,0$ \\
\hline
\end{tabular}

Table 2. Test Result of Coarse Aggregates Physical Properties Test

\begin{tabular}{|c|c|c|c|c|}
\hline \multirow{3}{*}{ Kind of Test } & & & \multirow{3}{*}{ Unit } & \multirow{3}{*}{ Spesification } \\
\hline & \multicolumn{2}{|c|}{ Coarse Aggregates } & & \\
\hline & $1: 2$ & $1: 1$ & & \\
\hline Sieve Analysis & 8,78 & 6,67 & - & - \\
\hline Bulk Spesific Gravity & 2,61 & 2,45 & - & $\operatorname{Min} 2,5$ \\
\hline SSD Spesific Gravity & 2,65 & 2,48 & - & $\operatorname{Min} 2,5$ \\
\hline Absorption & 0,96 & 0,78 & $\%$ & $\operatorname{Max} 3,0$ \\
\hline Abration Test & 20,76 & 11,17 & $\%$ & $<40$ \\
\hline
\end{tabular}

Table 3. Test Result of Asphalt Physical Properties Test

\begin{tabular}{|c|c|c|c|c|}
\hline Kind of Test & Result & Unit & Spesification & Explanation \\
\hline Spesific Gravity & 1,01 & - & $\geq 1,0$ & Qualify \\
\hline Asphalt Softening Point & 50,5 & ${ }^{\circ} \mathrm{C}$ & $\geq 49$ & Qualify \\
\hline Asphalt Penetration & 62,5 & $\mathrm{Mm}$ & $55-68$ & Qualify \\
\hline
\end{tabular}

Table 4. Test Result of Portland Cement Physical Properties

\begin{tabular}{|c|c|c|c|c|}
\hline Kind of Test & Result & Unit & Spesification & Explanation \\
\hline Spesific Gravity & 3,08 & $\mathrm{Kg} / \mathrm{m}^{3}$ & $3-3,20$ & Qualify \\
\hline Cement consistency & 10 & $\mathrm{Mm}$ & $10 \pm 1 \mathrm{~mm}$ & Qualify \\
\hline
\end{tabular}




\subsection{Marshall Test to Get an Optimum Asphalt Content}

Marshall test to get an optimum asphalt was done by using a normal asphalt content which appropriate based on General Specification of Bina Marga 2010. The results that has been tested shown on Table 5 .

\subsection{Marshall Test Results Against Variations of Seashell Waste}

Marshall test on variations of anadara granosa shell waste was carried out to determine how the characteristics of asphalt by using seashell waste as a substitute for fine aggregate.

\subsubsection{Stability}

Stability tests are used to measure the maximum capacity of solid asphalt concrete to accept loads until plastic melting occurs. Stability testing was carried out using various variations and levels of asphalt shown on Figure 1.

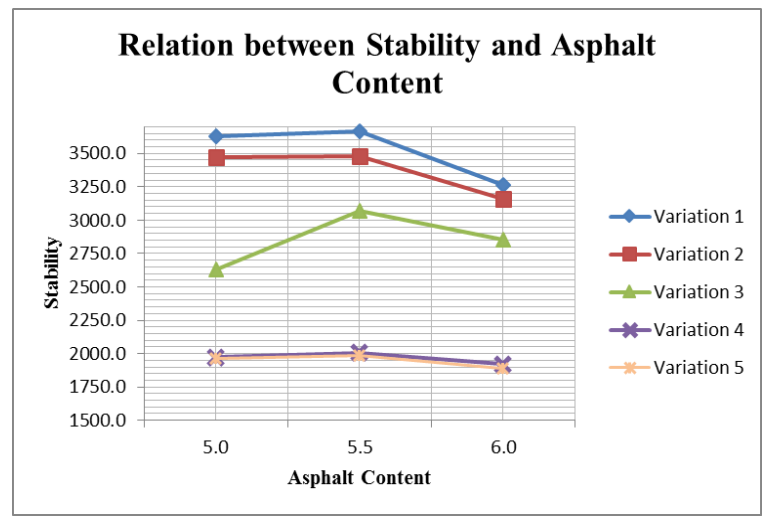

Figure 1. Relation between Stability and Asphalt Content Content
The stability graph of AC-WC mixture with several variations of the fine aggregate mixture with seashell waste and the addition of asphalt content in the $100 \%$ mixture of seashell waste aggregate (Variation 5) resulted in the lowest stability, while the fine aggregate of seashell waste was $25 \%$ (Variation 2) the highest stability. All variations are included in the General Specifications of Bina Marga 2010 Division 6 Asphalt Pavement for AC-WC (Asphalt Concrete Wearing Course) mixture with a minimum of $800 \mathrm{~kg}$. [13] The optimum value is asphalt content of $5.5 \%$. Lack of asphalt content will cause the surface to crack, and otherwise if it containt too much asphalt, it will make the surface layer bleeding. The highest value was obtained in 3666.0 at variation 1 asphalt content of $5.5 \%$ while the lowest value was obtained in 1886.0 at variation of 5 asphalt content of $6 \%$.

\subsubsection{Flow}

Flow is an amount of deformation or change in shape that occurs due to loads. Flow values are obtained from the flowmeter which expressed in units of $\mathrm{mm}$. Flow test was carried out using a wide variety of variations and asphalt shown on Figure 2.

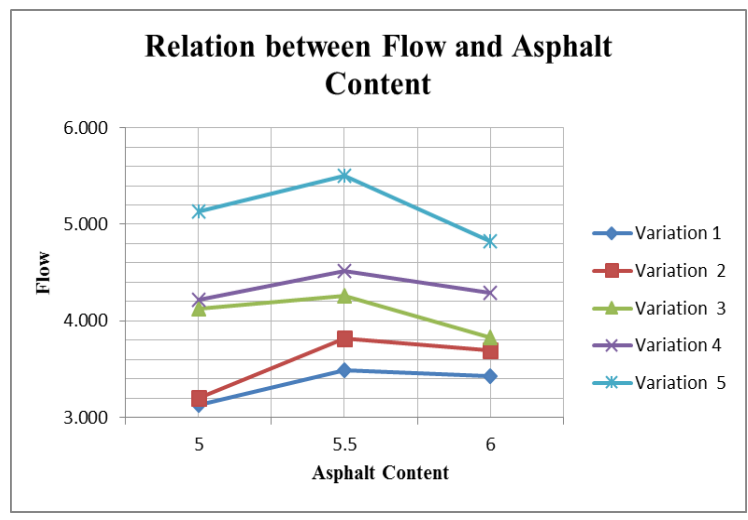

Figure 2. Relation between Flow and Asphalt

Table 5. Marshall Test Result

\begin{tabular}{|c|c|c|c|c|c|}
\hline No & Marshall Characteristics & 5 & 5.5 & 6 & Range \\
\hline 1 & Stability & 3631.0 & 3660.0 & 3264.0 & $>800 \mathrm{~kg}$ \\
\hline 2 & Flow & 3.125 & 3.489 & 3.422 & $>3$ \\
\hline 3 & VIM & 8.310 & 5.756 & 4.102 & $3-5$ \\
\hline 4 & VFA & 66.737 & 76.241 & 83.086 & $>65$ \\
\hline 5 & VMA & 24.976 & 24.218 & 24.241 & $>15$ \\
\hline 6 & Marshall Quotient & 805.403 & 704.113 & 620.119 & $>250$ \\
\hline
\end{tabular}


The flow graph of AC-WC mixture with various variations of the mixture of fine aggregate of seashell waste and the addition of asphalt content in the $25 \%$ mixture of seashell waste aggregate (Variation 2) resulted in the lowest flow, while the fine aggregate of seashell waste $100 \%$ (Variation 5) produces the highest flow. All variations are ncluded in the specification with a minimum is $3 \mathrm{~mm}$.[13] The optimum value obtained at Variation 5 asphalt content is $5.5 \%$, it is about 5.502 . The higher the flow value, the more elastic the surface of asphalt layer receives the load. But if the flow value is low, the potential for cracks on the asphalt surface will be even higher. The value obtained was 5.502, the value of variation 5 asphalt content was $5.5 \%$, while the lowest value was found to be 3.152 at variation 1 asphalt content of $5 \%$.

\subsubsection{Voids In the Mix (VIM)}

Voids in the mix (VIM) is the total volume of air between the asphalt-covered aggregate particles in a compacted mixture, and it expressed in percent of the bulk volume. Voids in the mix (VIM) testing was carried out using various variations and asphalt content shown on Figure 3.

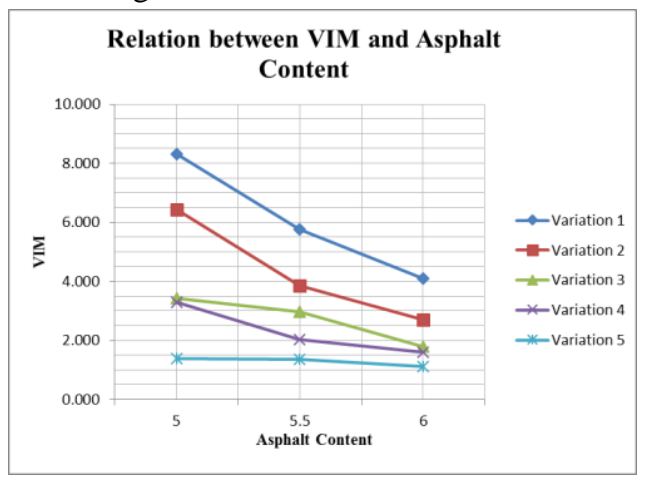

Figure 3. Relation between VIM and Asphalt Content

Voids In the Mix (VIM) graph of AC-WC mixture with various variations of the fine aggregate mixture of seashell waste and the addition of asphalt content in the $100 \%$ seashell waste aggregate mixture (Variation 5) produce the lowest VIM, while the fine aggregate shellfish waste $0 \%$ (Variation 1) get the highest VIM value. If the number of VIM get too large result, it will make the asphalt layer lack of impermeable to water and air so that the pavement layer is easily oxidized and get damaged. Otherwise, if number of VIM that is too small it will cause the pavement to be bleeding as the temperature increases. The highest value was 8,310 at variation 1 asphalt content $5 \%$, while the lowest value was 1,105 at variation 5 asphalt content $6 \%$.

\subsubsection{Voids in the Minerals Aggregate(VMA)}

Voids in the Minerals Aggregate (VMA) is the number of pores between aggregate grains in asphalt concrete. The minimum value of VMA is determined based on the General Specifications of Bina Marga 2010 Division 6, which is $15 \%$ [13] because if the VMA is too low it can cause an asphalt surface become bleeding. VMA testing is carried out using a few variations and different asphalt content shown on Figure 4.

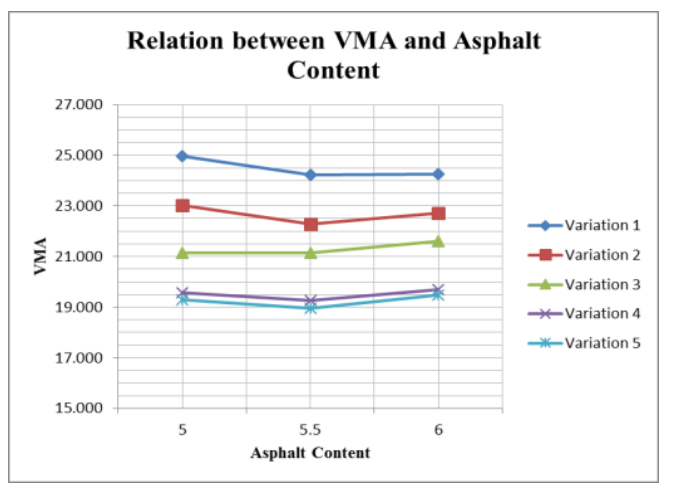

Figure 4. Relation between VMA and Asphalt Content

From the Voids in the Minerals Aggregate (VMA) graph, a mixture of $\mathrm{AC}-\mathrm{WC}$ with various variations of the fine aggregate mixture of seashell waste and the addition of asphalt content in the $100 \%$ seashell waste aggregate mixture (Variation 5) produce the lowest VMA, while the fine aggregate seashell waste $0 \%$ (Variation 1) produced the highest VMA value. All variations are included in the specification with a minimum of $15 \%$. [13]

As higher the VMA value, the more cavities in the mixture are filled with asphalt so that the water and air resistance of the mixture is higher. If the value of VMA is too high, it can containt a higher potential for bleeding on the pavement when receiving loads at high temperatures. Otherwise, if it has too low VMA value, it indicates a small amount of asphalt filling the cavity, so that it will cause the layer to be less able to bind the aggregate which results in the pavement being prone to stripping. The highest value was obtained 24,976 at variation 1 asphalt content $5 \%$, while the lowest value was 18,961 at variation 5 asphalt content of $5.5 \%$. 


\subsubsection{Voids Filles Asphalt (VFA)}

Voids Filles Asphalt (VFA) is the pore volume of asphalt concrete that is filled with asphalt. General Work (2010) requires a minimum value of VFA is $65 \%$. [13] VFA testing is carried out using various variations and asphalt content shown on Figure 5.

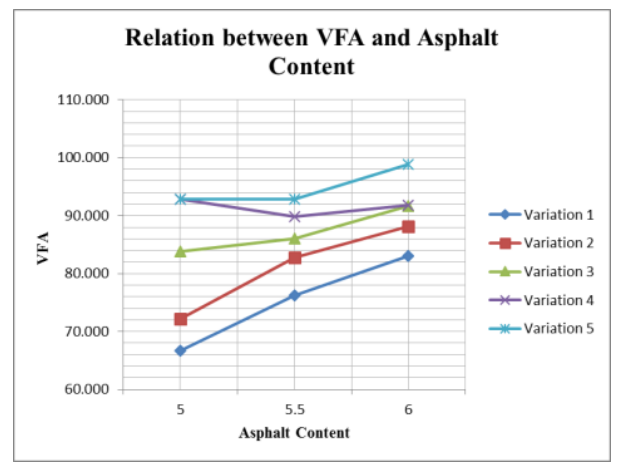

Figure 5. Relation between VFA and Asphalt Content

As the graph result of VFA, AC-WC mixture with various variations of the fine aggregate mixture of seashell waste and the addition of asphalt content in the $0 \%$ mixture of seashell waste aggregate (Variation 1) produce the lowest VFA, while fine aggregate with $100 \%$ seashell waste (Variation 5) produce the highest VFA value. In this test, all variations are included in the specification with a minimum of $65 \%$ [13]

If the VFA value is too high, it will cause the asphalt to rise to the surface at high pavement temperatures, but if the VFA value is too low, the mixture will be porous and easily oxidized. The highest value was obtained value 98.821 at variation 5 asphalt content $6 \%$, while the lowest value was obtained 66.737 at variation 1 asphalt content $5 \%$.

\subsubsection{Marshall Quotient (MQ)}

Marshall Quotient (MQ) is the ratio of stability to flow used as an indicator of mixed stiffness. Stability testing was carried out by using various variations and asphalt content shown on Figure 6.

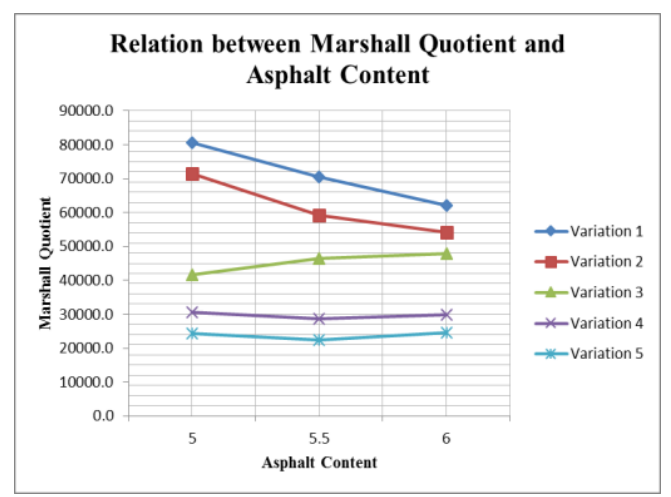

Figure 6. Relation between Marshall Quotient and Asphalt Content
Marshall Quotient (MQ) graph of AC-WC mixture with various variations of fine aggregate mixture of seashell waste and addition of asphalt content in 100\% mixture of seashell waste aggregate (Variation 5) produce the lowest $\mathrm{MQ}$, while the mixture of fine aggregate with $25 \%$ seashell waste (Variation 2) produce the highest MQ value. It shows that as increase the percentage of seashell waste, the lower the MQ value will be.

As higher the MQ value, the stiffer the mixture is. While the MQ with a low value will make the mixture being more flexible, tends to be elastic and it is easy to get a deformation if it gets load on it. The highest value was obtained 80540.3 at variation 1 asphalt content $5 \%$ while the lowest value was obtained 22345.7 at variation 5 asphalt content $5.5 \%$.

\section{CONCLUSION}

Base on result obtained we can conclude that:

1. The optimum value of stability testing is obtained at Variation 1 asphalt content of $5.5 \%$, it is 3.66 . The stability value has decreased, it indicates that the increase in percentage of Anadara Granosa's shell waste, the lower the stability value obtained.

2. The optimum value of flow testing is obtained at Variation 5 asphalt content of $5.5 \%$, it is 5.502 . The value of flow tends to increase, it shows that the increase in the percentage of anadara granosa's shell waste, the higher the flow value obtained.

3. The optimum value of VIM testing is obtained at Variation 2 asphalt content of $5.5 \%$, it is 3.845 . VIM value has decreased, it indicates that the increase in percentage of Anadara Granosa's shell waste, the lower the VIM value obtained.

4. The optimum value of VMA testing is obtained at Variation 1 asphalt content of $5 \%$, it is 24.976 . VMA value has decreased, it indicates that the increase in percentage of Anadara Granosa's shell waste, the lower the VMA value obtained.

5. The optimum value of VFA test is obtained at Variation 5 asphalt content of $6 \%$, it is 83.086 . The value of VFA tends to increase, it shows that the increase in the percentage of anadara granosa's shell waste, the higher VFA value obtained

6. The optimum value of MQ testing is obtained at Variation 1 asphalt content of $5 \%$, it is 805.403 . MQ value has decreased, it indicates that the increase in percentage of Anadara Granosa's shell waste, the lower the VIM value obtained.

\section{ACKNOWLEDGMENTS}

We would like to thank to State Polytechnic of Sriwijaya for facilitating laboratory for this research. 


\section{REFERENCES}

[1] Sukirman,Silvia. 2003. Flexible Pavement. Bandung.

[2] Saodang, H., 2005. Highway Construction. Bandung: Nova.

[3] Alamsyah, Alik Ansyori. 2018. The Influence of Green Seashell Waste as a Substitate of Fine Aggregates with Marshall Test Value in Sand Sheet- B

[4] Indonesian National Standard, 1990.No 03-1968. About Testing Methods Analysis of Fine and Coarse Aggregate Sieve.

[5] Indonesian National Standard, 1990.No 03-1969. Density Testing Methods and Absorption of Coarse Aggregate Water.

[6] Indonesian National Standard, 1990.No 03-1970. Density Testing Methods and Fine Aggregate Water Absorption.
[7] Indonesian National Standard, 1991. No 03-2417. Aggregate Wear Testing Methods With Los Angeles Abrasion Machines.

[8] Indonesian National Standard, 1991. No 06-2441. Density Testing Methods for Solid Asphalt.

[9] Indonesian National Standard, 1991. No 06-2434. Testing Methods for Asphalt and Tar Soft Points.

[10] Indonesian National Standard, 1991. No 06-2456. Testing Methods for Penetration of Bitumen Materials.

[11] Indonesian National Standard, 1991. No 03-2531. Portland Cement Density Testing Method.

[12] Indonesian National Standard, 2002.No 03-6826. Method of Testing the Normal Consistency of Portland Cement Using Vicat Equipment for Civil Works.

[13] Bina Marga. 2010. Draft General Specifications for Roads and Briges Division VI for Asphalt Pavement. Public Worck Departement 